\title{
Synthesis and characterization of MgO/PEG/GO Nanocomposite and its application for removal of Copper (II) from aquatic media
}

\author{
Susan SAMADI ${ }^{1, *}$, Maryam ABBASZADEH ${ }^{1}$ \\ ${ }^{1}$ Department of Chemistry, College of Basic Science, Yadegar-e-Imam Khomeini (RAH) \\ Shahr-e-Rey Branch, Islamic Azad University, Tehran, Iran \\ *Corresponding author e-mail: susansamadi@iausr.ac.ir
}

\begin{abstract}
In this study, $\mathrm{MgO} / \mathrm{PEG} / \mathrm{GO}$ nanocomposite was synthesized by a sol-gel and solvothermal methods. with three chemical compounds that had adsorption property. Microstructure of synthesis nanocomposite was investigated by XRD, SEM and FT-IR. The XRD pattern confirms crystalline structure of $\mathrm{MgO}$ and GO. The SEM images validate formation of $\mathrm{MgO}$ particles on GO layers in Nano size. The analysis EDX is shown in the presence of magnesium and FT-IR result shows expected structure. The $\mathrm{MgO} / \mathrm{PEG} / \mathrm{GO}$ nanocomposite was used for removing copper (II) ion from water and the effective factors on removal were optimized. The results showed that the maximum of removal in $\mathrm{pH}$, amount of adsorbent and contact time are equal to 7,0.01 $\mathrm{g}$ and 20 minutes respectively. Investigating the effect of interfering ions had no considerable effect on removal efficiency.
\end{abstract}

Keywords: Graphene oxide, Magnesium oxide, Nanocomposite, Heavy metal.

\section{Introduction}

It's believed that exposure to heavy metal can be harmful for human health even at the trace level ${ }^{1}$. Therefore, finding useful methods and applying them efficiently have always been vital $^{2,3}$. Today, there are various methods that can be suggested for removing heavy metal from water such as cementation ${ }^{4}$ electro deposition ${ }^{5}$, ion exchange ${ }^{6}$, precipitation $^{7}$ and etc. Adsorption is one of these methods which provides flexibility in design and operation. It also produces effluent that's treated with a high quality manner. Consequently, adsorption is regarded as a pioneer technique that can be used for removing metal from water or wastewater.

There are various researches that have been conducted on efficient and inexpensive methods of natural absorbents with the aim of removing heavy metal ions from water. They are namely activated biomass $^{3}$, natural and synthesized clay ${ }^{8,9}$.

However, currently, new adsorbent has been made through nanotechnology which has a high specific surface area and it has an inordinate function ${ }^{10}$.

Inorganic hybrid polymers have facilitated different practices such as removing heavy metal ion by nanosorbents ${ }^{11}$. In order to synthesis the inorganic hybrid material and mesomorphous compounds, sol-gel method are used. There are nanoparticles which have been used in such hybrids. They are namely $\mathrm{SiO}_{2}{ }^{12}, \mathrm{Al}_{2} \mathrm{O}_{3}{ }^{13}, \mathrm{Fe}_{3} \mathrm{O}_{4}{ }^{14}, \mathrm{ZnO}^{15}, \mathrm{ZrO}_{2}{ }^{16}, \mathrm{CdS}^{17}$, and $\mathrm{MgO}^{18}$. 
Magnesium oxide $(\mathrm{MgO})$ nanostructures have drawn special attention because of their important applications in the areas of catalysis, refractory materials, and superconductors ${ }^{19-}$ ${ }^{21}$.Various $\mathrm{MgO}$ structures, such as nanocrystals, nanoparticles, nanocubes, nanowires, and nanosheets have been fabricated successfully ${ }^{22-24}$. For the field of surface chemistry, including such areas as catalysis and adsorption, the fabrication of $\mathrm{MgO}$ nanostructures with high surface area and robustness is a priority. In recent decades, $\mathrm{MgO}$ and graphene oxide are used to synthesize different nanocomposites ${ }^{18}$.

Graphene oxide nanosheets, a single layer consisting of $\mathrm{sp}^{2}$-bonded carbon atoms, have attracted considerable scientific interest due to their excellent thermal, mechanical, and electronic properties ${ }^{25-27}$. Building of nanocomposites of inorganic nanoparticles onto a graphene sheet would yield the benefit of large surface area ${ }^{28}$. Research into nanocomposites of graphene and inorganic nanoparticles have mostly used chemically exfoliated graphene and its derivatives, such as graphene oxides (GO) and reduced graphene oxides (RGO). Because these materials can act as substrates to support adhered inorganic nanoparticles, the resulting nanocomposites can exhibit enhanced properties for adsorption and sensing applications.

In this research, $\mathrm{MgO} / \mathrm{PEG} / \mathrm{GO}$ nanocomposite was synthesized with growth $\mathrm{MgO}$ nanoparticles on graphene oxide and PEG by using a sol-gel and solvothermal methods. This nanosorbent was used to remove of $\mathrm{Cu}^{2+}$ ion from aquatic media and then the parameters that affect the elimination process were perfectly used.

\section{Materials and method}

\subsection{Chemicals and reagents}

Graphite flake, polyethylene glycol (PEG), hydroxyl propyl cellulose (HPC) prepared from Sigma-Aldrich. $\mathrm{KClO}_{3}, \mathrm{H}_{2} \mathrm{SO}_{4}, \mathrm{HNO}_{3}$ and absolute $\mathrm{C}_{2} \mathrm{H}_{5} \mathrm{OH}$, with analytical grade, obtained from Merck, and deionized water.

\subsection{Synthesis of $\mathrm{MgO} / \mathrm{PEG} / \mathrm{GO}$ nanocomposite}

GO was prepared by the Staudenmaier method. Briefly, graphite flakes ( $1 \mathrm{~g})$ were added to an acid mixture: $9 \mathrm{~mL}$ of $\mathrm{HNO}_{3}$ and $18 \mathrm{~mL}$ of $\mathrm{H}_{2} \mathrm{SO}_{4}$ in a beaker with vigorous stirring with a magnetic stirrer. An amount of $11 \mathrm{~g}$ of the oxidizing agent $\left(\mathrm{KClO}_{3}\right)$ was slowly added to the mixture in 3 hours with a temperature lower than $10{ }^{\circ} \mathrm{C}$. Then, it was released to the ice bath for an hour. The solution was removed from ice bath and it was mixed with an intense stirring for 10 days in a moderate temperature.

Then, the graphite oxide slurry was washed thoroughly with an $\mathrm{HCl}$ solution and deionized water several times and dried in a vacuum oven for $4 \mathrm{~h}$ at $85{ }^{\circ} \mathrm{C}$. Then, $0.1 \mathrm{gr}$ of graphite oxide was released in $40 \mathrm{~mL}$ of deionized water and $40 \mathrm{~mL}$ of ethanol under ultrasonic condition for 2 hours. After that, the solution was centrifuged and located in vacuum oven for 2 hours. This led the graphite oxide layers to be separated from graphene oxide form. The FT-IR spectroscopy and X-ray diffraction were used to perform the compound's characterization.

On the other hand, $\mathrm{MgCl}_{2}$ was dissolved in deionized water. Subsequently, HPC was added to the solution in a ratio of 3:5 and additional $250 \mathrm{ml}$ of $\mathrm{NaOH}$ solution under 
vigorous stirring for $4 \mathrm{~h}$. This solution is centrifuged and washed with distilled water and absolute ethanol. The obtained colloidal suspension was dried to obtain magnesium oxide.

In order to synthesis $\mathrm{MgO} / \mathrm{PEG} / \mathrm{GO}$ nanocomposite, firstly, $0.3 \mathrm{~g}$ of graphene oxide was poured in to breaker and secondly, $70 \mathrm{ml}$ of absolute ethanol was added to the solution. Then, it was located in an ultrasonic bath for an hour till it gets perfectly dispersed. After that, $0.3 \mathrm{~mL}$ Peg polymer and $0.3 \mathrm{~g}$ of $\mathrm{MgO}$ were added to that solution which was located in the ultrasonic bath till it gets perfectly mixed. Finally, it was located in a vacuum oven for 48 hours at $50^{\circ} \mathrm{C}$ till it gets dry and to be milled by planetary ball mill and to be kept for the tests.

\subsection{Characterization}

Sartorius precision hot 0/0001 AB204-S models made in Germany, pH meter Manufacturing Co. Model PB-11 Sartorius, Universal 320 Hettich centrifuge model scales, Ultrasonic bath Elmasonic $60 \mathrm{H}$ model, conventional oven Memmert. Hytr-stirrer Standard Heidolph/mrhei 91126D models made in Germany, Model PM100Retsch planetary mill, Scanning electron microscopy (SEM), model EM3200 Manufacturing Co.KYKY, Flame atomic absorption spectrophotometry Atomic Absorption Spectrophotometer Flame 990 model Manufacturing Co. PG England. Devices X-ray inel model EQUINOX 3000, Philips device EDAX XLC and Spectrophotometry FT-IR, Tensor 27Bruker model using tablet KBr.

\section{Results and discussion}

\subsection{Microstructure of MgO/PEG/GO nanocomposite}

Figure 1a and 1b show the SEM images of graphene oxide and MgO/PEG/GO.

Figure 1.a also shows the full observation of graphene oxide's layer structure and proves its synthesis. Layer structure of graphene oxide is obvious in figure 1b. It also produced nanoparticle that are related to $\mathrm{MgO}$. The graphene oxide thickness increases after the nanocomposite synthesis can be related to the PEG polymer which is on the graphene oxide's surface.

By changing the $\mathrm{MgO}$ growth condition, controlling average particle sizes and size distribution can be achieved.

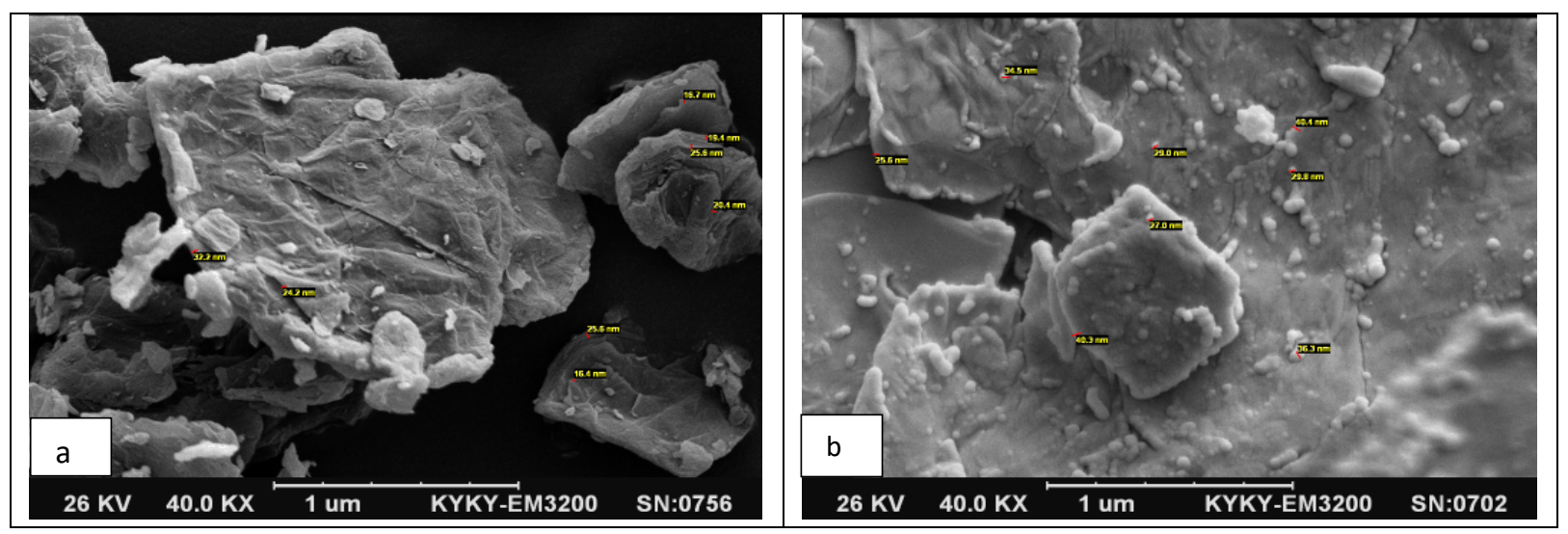

Fig. 1: SEM images of (a) Graphene Oxide and (b) MgO/PEG/GO nanocomposite 
Figure 2 shows the EDX analyses result of nanocomposite and also magnesium element in synthesized nanocomposite.

The graphene oxide's crystal structure and synthesized nanocomposite were assessed by XRD analysis. Figures $3 \mathrm{a}$ and $3 \mathrm{~b}$ respectively show the XRD pattern of GO and $\mathrm{MgO} / \mathrm{PEG} / \mathrm{GO}$ nanocomposite. The apex in figure $3 \mathrm{a}\left(2 \theta=11.9^{0}\right)$ shows the succession and It is similar to the1plan diffraction $\left(\mathrm{d}_{001}=7.4 \AA\right.$ )

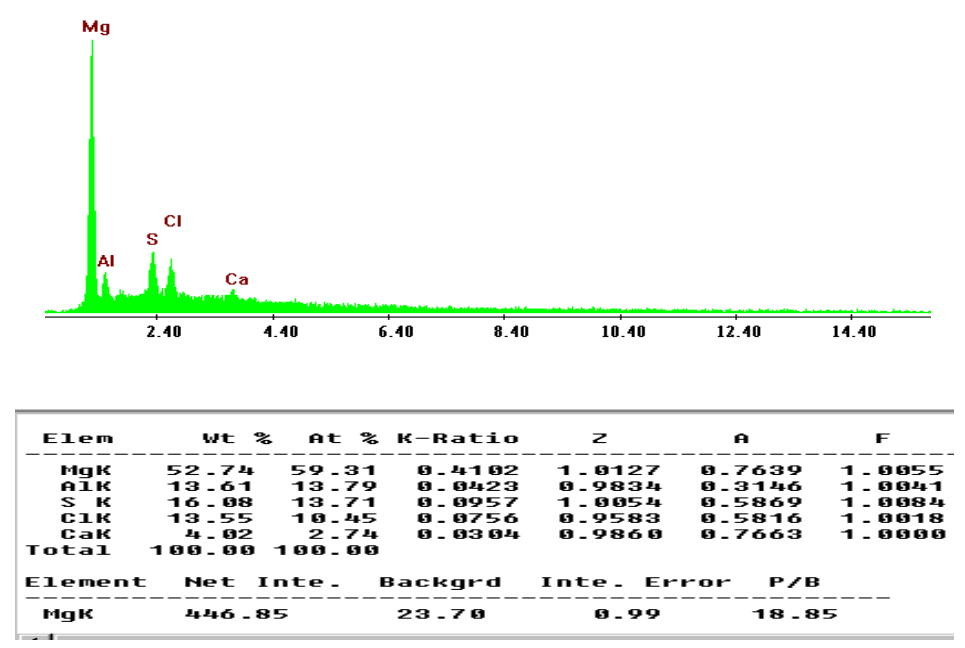

Fig. 2: $\mathrm{EDX}$ analysis of $\mathrm{MgO} / \mathrm{PEG} / \mathrm{GO}$ nanocomposite

The XRD pattern of synthesized nanocomposite in Fig. 3b, clearly confirmed the presence of the $\mathrm{MgO}$ cubic phase with a lattice parameter of $a=b=c=4.213^{\circ} \mathrm{A}$ and

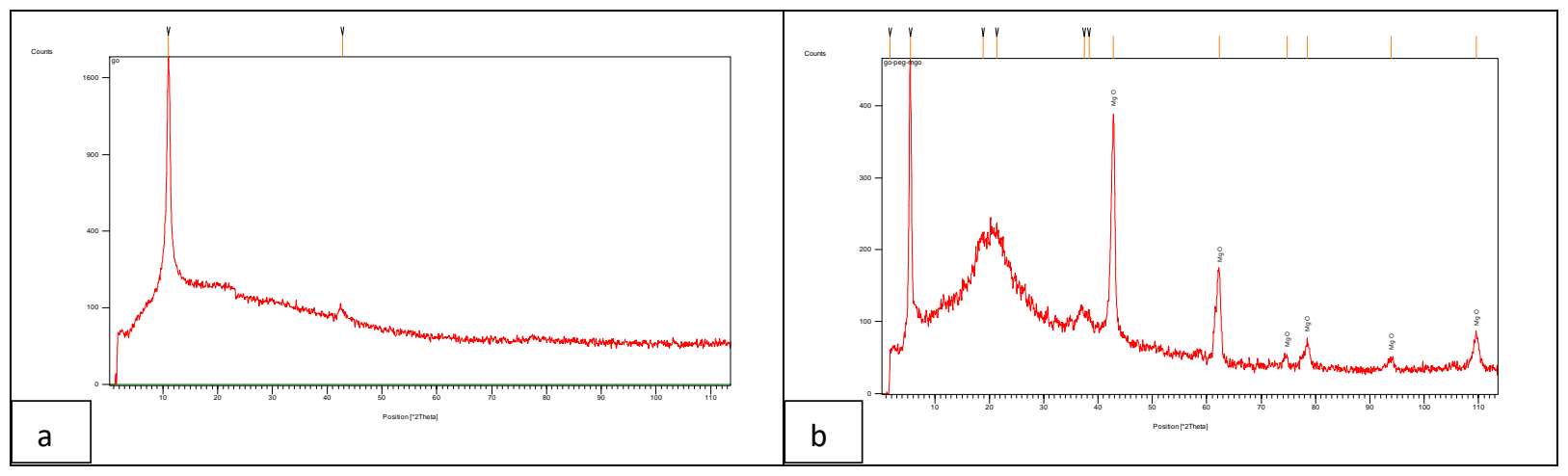

Fig. 3: XRD pattern of (a) GO and (b) $\mathrm{MgO} / \mathrm{PEG} / \mathrm{GO}$ nanocomposite

space group (Fm-3m (225)) and the diffraction peaks at $2 \theta$ values of $37.44^{0}, 38.32^{0}, 62.36^{0}$, $74.76^{\circ}$, and $78.42^{029}$.

Fourier-transform infrared spectroscopy (FT-IR) was used to identify the functional groups in a compound. FT-IR spectrum of $\mathrm{MgO} / \mathrm{PEG} / \mathrm{GO}$ nanocomposite is shown at Fig. 4. The stretching vibration mode for the $\mathrm{Mg}-\mathrm{O}-\mathrm{Mg}$ compound is seen in $422.45 \mathrm{~cm}^{-1}$. A broad 
vibration band at wave number range $3362.67-3703.77 \mathrm{~cm}^{-1}$ is assigned to surface hydroxyl group. This is due to the aerial adsorptions of water molecule onto the $\mathrm{MgO}$ surface when it is exposed to atmosphere. The strong peaks at $2875 \mathrm{~cm}^{-1}, 1642 \mathrm{~cm}^{-1}$ and $841.45 \mathrm{~cm}^{-1}$ have been assigned to $\mathrm{C}-\mathrm{H}, \mathrm{CO}-\mathrm{NH}$ and $\mathrm{C}-\mathrm{O}$, respectively. They are stretching peaks for $\mathrm{GO}-$ $\mathrm{PEG}^{30,31}$.

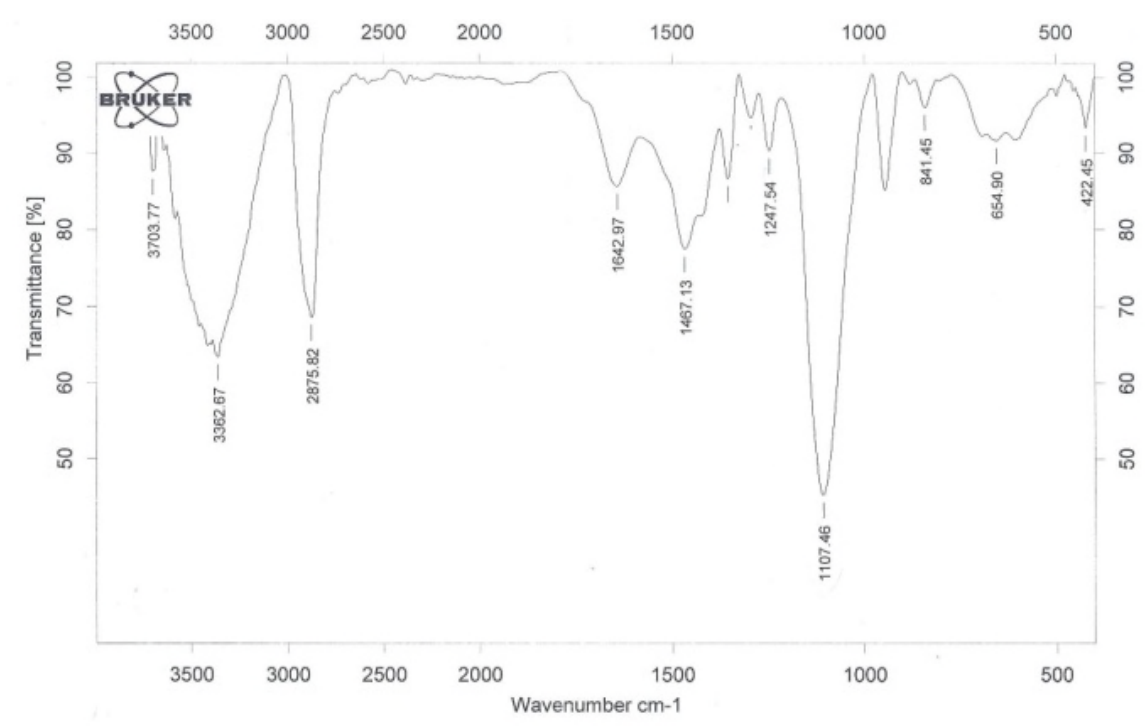

Fig. 4: FT-IR spectrum of MgO/PEG/GO nanocomposite

\section{Removal study by use of nanocomposite}

The effectiveness of different factors such as $\mathrm{pH}$, contact time, adsorbent dosage and solution volume was assessed to find best condition for receiving the maximum absorption efficacy. A parameter was regarded as a variable and the others were regarded as constant.

\section{1. $\quad$ Effect of $\mathbf{p H}$}

The scope of $\mathrm{pH}=3-7$ was analyzed in order to investigate the $\mathrm{pH}$ effectiveness on copper (II). The ions are precipitated as hydroxide where $\mathrm{pH}$ is higher than 7 . Thus, they weren't analyzed. Figure 5 shows the result of copper (II) ion removal by $\mathrm{MgO} / \mathrm{PEG} / \mathrm{GO}$ nanocomposite. When $\mathrm{pH}$ increases, ion removal also increases by synthesized nanosorbent and the maximum rate of removal can be observed at $\mathrm{pH}=6$ and 7. It's clear that $\mathrm{H}_{3} \mathrm{O}^{+}$ions compete with coper (ii) ion in acidic $\mathrm{pH}$ in order to keep active sites in synthesized nanocomposite which consequently leads to removal inefficacy. 


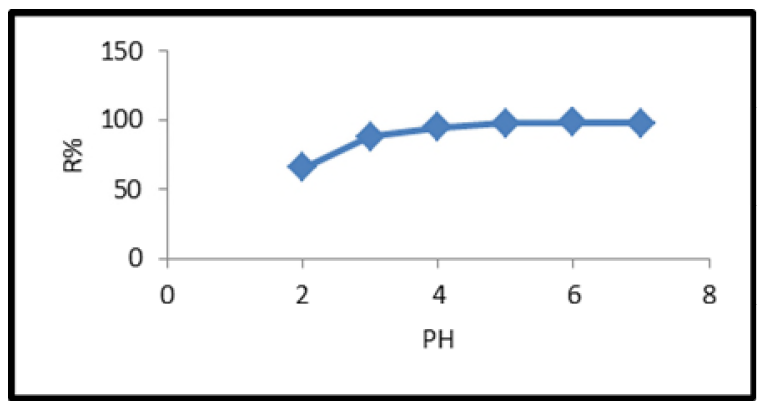

Fig. 5: Effect of pH on removal of Copper (II) ion from aqueous sample

Therefore, $\mathrm{pH}=7$ was regarded as the best value for the $\mathrm{pH}$.

\subsection{The effectiveness of sorbent dosage}

In order to analyze the effectiveness of sorbent dosage on removing heavy metal ions from water, the removal process was separately performed for $0.005,0.01,0.015,0.02,0.0 .25$ $\mathrm{g}$ of prepared nanocomposite at $\mathrm{pH}=7$. The results are shown in figure 6. 0.01 grams (for Mgo/PEG/GO nonocomposite) was the highest percentage which was received from the copper (II) ion removal. It's obvious that by increasing the nanosorbent dosage, the active sites will also increase for the adsorption of ions. Moreover, the removal efficacy will be increased until all ions are absorbed in the sample. After that point, the increase of sorbent dosage has no effectiveness.

\subsection{Effect of removal time}

Enough time was required for the adsorption of copper (II) ion so that the active sites could be handled on the adsorbent. Consequently, copper removal (ii) was separately repeated at 10, 20, 30, 40, and 50 minutes at prefered condition. Figure 7 shows the result of $\mathrm{Cu}^{2+}$ by synthesized nanocomposite.

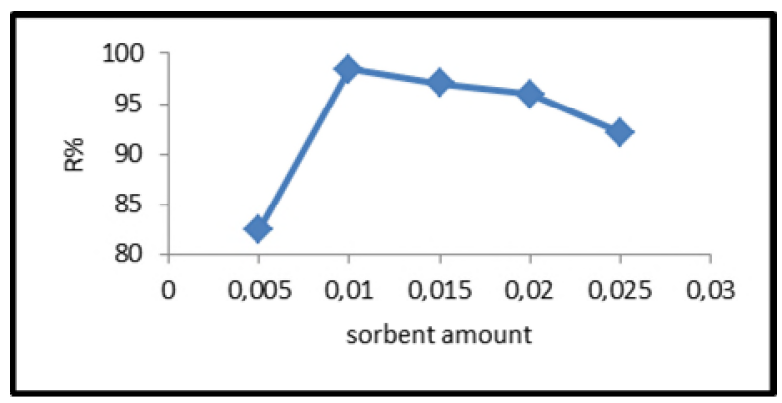

Fig. 6: Effect of sorbent amount in removal process 


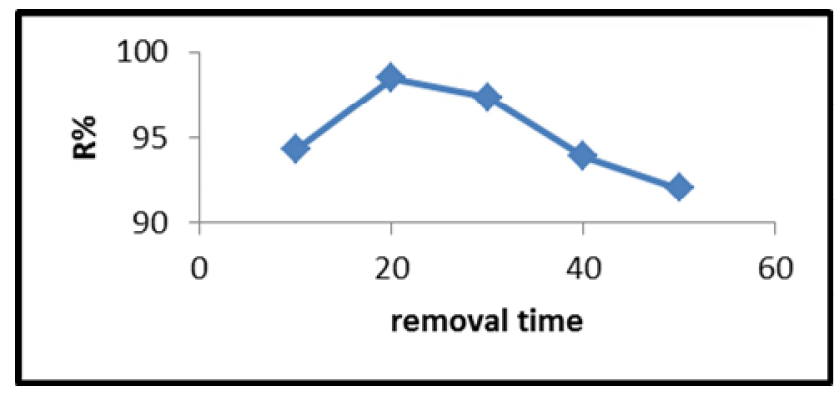

Fig. 7: Effect of time in removal process

It is obvious that the removal's maximum amount was obtained at 20 minutes. Therefore, increasing the contact time leads to the removal efficacy increase. Although much more time is needed for the ions in solution to be adsorb on active sites, but the further increase in time won't affect the removal after the ions absorption.

\subsection{Interference ions effectiveness}

The removing process of copper (II) ion was repeated in the proper condition in order to analyze the interference effects other ions. This has occurred in the presence of $\mathrm{K}^{+}$, $\mathrm{Na}^{+}, \mathrm{Mg}^{2+}, \mathrm{Ca}^{2+}, \mathrm{Zn}^{2+}, \mathrm{Fe}^{2+}$ and $\mathrm{Fe}^{3+}$ as interfering ions where their molar ratio was hundred times higher than copper (II)ion. Table 1 shows the results. This effect can be insignificant if the removal change is around $\pm 5 \%$ in the presence of interfering ions. The results reveal that different ions has no significant impact on the adsorption of copper (II) by nanocomposite. The removal rate also turned out to be proper and satisfactory. 
Table 1: Investigation of interfering ions effect at concentration level of $5 \mathrm{mg} / \mathrm{L}$ on removal of copper (II) ion (molar ratio were hundred times greater than $\mathrm{Cu}^{2+}$ ) by $\mathrm{MgO} / \mathrm{PEG} / \mathrm{GO}$ nanocomposite

\begin{tabular}{|c|c|}
\hline $\begin{array}{c}\text { Efficiency } \\
(\%)\end{array}$ & $\begin{array}{c}\text { Interfering } \\
\text { ions }\end{array}$ \\
\hline $94.86 \pm 1.23$ & $\mathrm{~K}^{+}$ \\
\hline $94 \pm 1.54$ & $\mathrm{Na}^{+}$ \\
\hline $97 \pm 2.1$ & $\mathrm{Fe}_{(\mathrm{II}, \mathrm{III})}$ \\
\hline $96.5 \pm 1.8$ & $\mathrm{Zn}^{2+}$ \\
\hline $93 \pm 1.4$ & $\mathrm{Ca}^{2+}$ \\
\hline $94 \pm 1.7$ & $\mathrm{Mg}^{2+}$ \\
\hline
\end{tabular}

Put differently, the removal process stay unaffected where the synthesized nanocomposite is suitable for $\mathrm{Cu}^{2+}$ ion removal and the ion irritates others.

\subsection{The method reproducibility}

The copper (II) ions removal was repeated five times by by $\mathrm{MgO} / \mathrm{PEG} / \mathrm{GO}$ nanocomposite under an optimal condition in order to evaluate the method's reproducibility. The efficacy of the removal was estimated at each stage and the RSD values turned out to be $1.1 \%$. The results were acceptable and the copper (II) ion removal in prepared nanocomposite revealed that it has a good reproducibility.

\section{Conclusions}

The main goal of this study was to provide a simple, efficient, reproducible and inexpensive method for removing heavy metal ions. In the present research, sol-gel and solvothermal methods were used to synthesize $\mathrm{MgO} / \mathrm{PEG} / \mathrm{GO}$ nanocomposite. The structure of nanocomposite was examined by XRD, SEM and FT-IR. The result of XRD revealed that $\mathrm{MgO}$ and graphene oxide have been developed. FT-IR spectroscopy proved to have a good structure and SEM images shows the layer structure of graphene oxide and development of $\mathrm{MgO}$ nanoparticles on it.

In order to remove copper (II) ion, the synthesized nanocomposite was used as adsorbents. There are factors that can affect the adsorption ability, for example $\mathrm{pH}$, contact time and adsorbent dosage which were all analyzed. The study shows that the interference ions have no effectiveness on the copper (II) ion extraction made by synthesized nanocomposite and the percentage of the recovery turned out to be satisfactory.

\section{Acknowledgements}

The authors are grateful to the Laboratory Complex of Yadegar-e-Imam Khomeini (RAH) Shahr-e-Rey Branch, Islamic Azad University for valuable technical assistance. 


\section{References}

1. Adebayo, A. O. Bull. Chem. Soc. Ethiop. 2013, 27(1), 25-34.

2. Sara vanan, D.; Gomathi T.; Sudha, P. N. Int. J. Biol. Macromol. 2013, 53, 67-71.

3. Ahmad, A.; Ghufran, R.; Mohd Faizal, W. Clean, 2010, 38(2), 153-158.

4. Bramat, M. El Coll De Boeck University France, 2007.

5. Grimshaw, P.; Calo, J. M.; Shirvanian, P. A.; Hradil, G. Ind. Eng. Chem. Res. 2011, 50(16), 9525-9531.

6. Dabrowski, A.; Hubicki, Z.; Pod koscielny, P.; Robens, E. Chemosphere. 2004, 56(2), 91-106.

7. Alfassi, Z. B.; Wai, C. M. CRC Press Boston MA. 1992.

8. Eba, F.; Ndong NLo, J.; Ondo, J. A.; Andeme EYi, P.; Nsi- Emvo, E. J. Environ. Earth Sci. 2013, 3(1), 11-23.

9. Anirudhan, T. S.; Jalajamony, S.; Sreekumari, S. S. Appl. Clay Sci. 2012, 65-66, 67-71.

10. Lu, Ch.; Chiu, H. Chem. Eng. Sci. 2006, 61, 1138-1145.

11. Samadi, S.; Khalilian, F.; Tabatabaee, A. J. Nanostruct. Chem. 2014, 4(48), 1-8.

12. Khayet, M.; Villaluenga, J. P. G.; Valentin, J. L.; Lopez-Manchado, M. A.; Mengual, J. A,; Seoane, B. Polymer, 2005, 47, 114-122.

13. Shen, J.Y.; Zhu, W. T.; Chen, L. Q.; Qiu, X. P. J. Power Sources. 2006, 159, 894-899.

14. Han, P.; Yahui, H.; Yang, W.; Linlin, L. J. Membr. Sci. 2006, 284, 9-16.

15. Huang, H.G.; Chen, J. H.; Zou, L. C. J. Rare Met. 2003, 27, 91-94.

16. Bottino, A.; Capannelli, G.; Comite, A. Desalination. 2002, 146, 35-40.

17. Trigo, C. E. L.; Porto, A. O.; De lima, G. M. Eur. Poly. J. 2004, 40, 2465-2469.

18. Dargahi, A.; Golestanifar, H.; Darvishi, P.; Karami, A.; Hasan, H.; Poormohammadi, A.; Behzadnia, A. Environ. Stud. 2016, 2, 557-562.

19. Li, W. C.; Lu, A. H.; Weidenthaler, C.; Schüth, F. Chem. Mater. 2004, 16, 5676-5681.

20. Makhluf, S.; Dror, R.; Nitzan, Y.; Abramovich, Y.; Jelinek, R.; Gedanken, A. Adv. Funct. Mater. 2005, 15, 1708-1713.

21. Ran Lee, j.; Young Koo, H. Sci.Tech. 2013, 4, 206-209.

22. Fang, X. S.; Ye, Ch.; Zhang, L. D.; Zhang, J. X.; Zhao, J. W.; Yan, P. small. 2005, 1, 422-426.

23. Stankic, S.; Müler, M.; Diwald, O.; Sterrer, M.; Knöinger, E.; Bernardi, J. Angew. Chem. Int. Ed. 2005,44, 4917-4920.

24. Zhu, K.; Hu, J.; Küel, C.; Richards, R. Angew. Chem. Int. Ed. 2006, 45, 7277-7281.

25. Novoselov, K. S.; Geim, A. K.; Morozov, S. V.; Jiang, D.; Zhang, Y.; Dubonos, S. V.; Grigorieva, I. V. Science. 2004, 306, 666-671.

26. Stankovich, S.; Dikin, D. A.; Dommett, G. H. B.; Kohlhaas, K. M.; Zimney, E. J.; Stach, E. A.; Piner. R. D.; Nguyen, S. T.; Ruoff, R. S. Nature. 2006, 422, 282-289.

27. Stoller, M. D.; Park, S.; Zhu, Y.; An, J.; Ruoff, R. S. Nano Lett. 2008, 8, 3498-3501.

28. Koo, H. Y.; Lee, H. J.; Go, H. A.; Lee, Y. B.; Bae, T. S.; Kim, J. K.; Choi, W. S. Materials Letters. 2011, 17, 1214-1217.

29. Nemade ,K. R.; Waghuley, S. A. Int. J. Metals. 2014, 389416,4

30. Kostiantyn, T.; Charle, H.; Laurent, H.; Svetlana, R.; Vladimir, Z.; Jolanda, S.; Rabah, B.; Sabine, S. Nano LIFE. 2015, 1. 12-16. 
Bulletin de la Société Royale des Sciences de Liège, Vol. 86, special issue, 2017, p. 271 - 280

31. Allen, M. J.; Yang, Y.; Kaner, R. B. Nature Nanotech. 2009, 4, 25-27. 